\title{
Poverty and abortion complications in Peru
}

Each year, approximately 20 million unsafe abortions - those performed by people lacking necessary skills or in environments lacking minimal medical standards, or both - take place worldwide, producing a variety of complications such as incomplete abortion, haemorrhage, sepsis, peritonitis, cervical, vaginal or uterine trauma, psychological problems, chronic infection, infertility, and death. ${ }^{1}$ Moreover, in countries where abortion is penalised, the incidence of unsafe abortions is 23 per 1000 women of childbearing age (WCA), considerably higher than the 2 per 1000 WCA observed in countries where abortion is not penalised. ${ }^{1}$

In Peru, abortion is illegal, except when it is the only option to prevent death or permanent health damage to the woman. In such cases, abortion is regulated by a technical guideline approved in 2014, which aims to improve access to this procedure, although it is not being broadly used by Peruvian doctors yet. When illegal, abortions are often performed clandestinely, which leads to great inequity as poor women have great difficulty accessing 
safe abortions, leading to large differences in complication rates between poor women (29.7\%) and affluent women $(0.8 \%){ }^{2}$ This situation seems worse in Peruvian highland and jungle cities, which have higher poverty rates, and where the annual incidence of induced abortion is higher than in the coastal cities $(3.1 \%$ in the highlands, $4.4 \%$ in the jungle and $2.4 \%$ on the coast). ${ }^{3}$

Peru has 25 departments - geographical subdivisions - so it is logical to suppose that women in the poorer departments have reduced access to health services for abortion complications. To test this hypothesis, we studied the relationship between poverty and the rate of abortion-related hospitalisations in Peru using an ecological approach at department level.

The number of hospital admissions for abortion-related complications at the Ministry of Health's hospitals during 2015 was requested through the Ministry's transparency portal. In Peru, in order to avoid legal problems for patients, health personnel usually do not register the diagnosis of induced abortion. Therefore, given the impossibility of evaluating induced abortion independently, we included all abortion hospitalisations for this analysis, excluding ectopic pregnancy, mole or other abnormal products of conception. For each department, we divided the number of abortion-related complications by the number of WCA.

The number of WCA and the poverty percentage in each Peruvian department for 2015 were obtained from the National Institute of Statistics and Informatics. Poverty percentage was assessed, considering as poor those persons whose per capita spending is insufficient to purchase basic needs (such as food, housing, clothing, health, among others).

We found that the rate of abortionrelated hospitalisations per 1000 WCA in Peruvian departments ranged from 2.0 to 13.2 , with an average of 5.8 . Having the departments as the unit of analysis, we were surprised to find that the percentage of total poverty was inversely proportional to the number of abortion-related hospitalisations per 1000 WCA (Spearman coefficient $-0.544 ; p=0.005$ ) (Figure 1).

As already mentioned, previous data have suggested that poorer departments

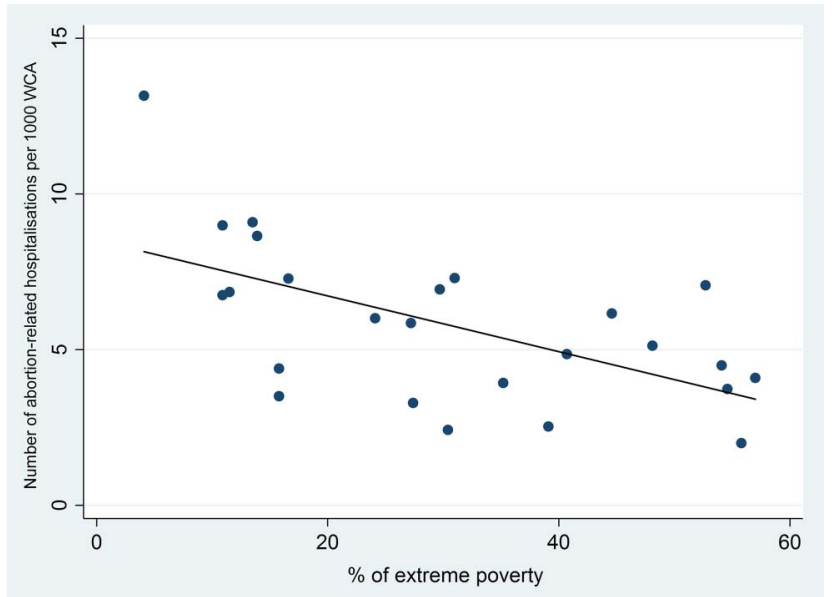

Figure 1 Association between rate of abortion-related hospitalisations by 1000 women of childbearing age (WCA) and percentage of total poverty by department, Peru.

should have higher rates of abortion complications. ${ }^{2}$ However, this is not reflected in our results, which showed an inverse association between poverty and abortion hospitalisations. This suggests that poorer women may have more difficulties in accessing health services when abortion complications develop compared with more affluent women, due to geographic barriers, unavailability of health services, and economic difficulties, ${ }^{4}$ which may force them to manage their complications on their own, or attend the nearest healthcare centres without reaching hospitals.

One study limitation we had was the impossibility of addressing induced abortion solely, given the low registration of induced abortion, therefore we had to consider all abortion-related hospitalisations for the analysis. However, the rate of induced abortion in this group has been estimated at $34 \%$ in a Peruvian hospital, ${ }^{5}$ so it is unlikely that our results have been severely altered by this limitation.

Our results suggest the existence of a double inequity, nested in the criminalisation of abortion in Peru, as poor women not only have greater rates of complications related to unsafe abortion, but also reduced access to hospitalisation when these complications appear. Thus, this subject should be studied in depth in order to generate strategies to protect the poorest women in our country.

\section{Jessica Hanae Zafra-Tanaka*}

Universidad Nacional Mayor de San Marcos, Lima, Peru; cherryzt@hotmail.com

\section{Nicolaz Merino-Garcia}

Facultad de Medicina Humana, Universidad de San Martín de Porres, Lima, Peru; nicolaz_mega27@ hotmail.com

\section{Alvaro Taype-Rondan}

CRONICAS Center of Excellence for Chronic Diseases, Universidad Peruana Cayetano Heredia, Lima, Peru; alvaro.taype.r@upch.pe

${ }^{*}$ Corresponding author.

Competing interests None declared.

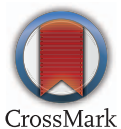

Published Online First 9 December 2016

J Fam Plann Reprod Health Care 2017;43:80-81. doi:10.1136/jprhc-2016-101606

\section{REFERENCES}

1 Grimes DA, Benson J, Singh S, et al. Unsafe abortion: the preventable pandemic. Lancet 2006;368:1908-1919.

2 Ferrando D. El aborto clandestino en el Perú. Lima, Peru: Centro de la Mujer Peruana Flora Tristán, 2006.

3 Bernabé-Ortiz A, White PJ, Carcamo CP, et al. Clandestine induced abortion: prevalence, incidence and risk factors among women in a Latin American country. CMAJ 2009;180:298-304.

4 Peters DH, Garg A, Bloom G, et al. Poverty and access to health care in developing countries. Ann N Y Acad Sci 2008;1136:161-171.

5 Sandoval-Paredes JdC. Aborto clandestino: Factores asociados, Impacto en la Salud Pública y Análisis de la Situación Legal [Doctoral dissertation]. Lima, Peru: Universidad Nacional Mayor de San Marcos, 2005. 